\title{
In Situ Transmission X-Ray Microscopy of the Lead Sulfate Film Formation on Lead in Sulfuric Acid
}

\author{
K. W. Knehr, ${ }^{a, *, z}$ Christopher Eng, ${ }^{b}$ Yu-chen Karen Chen-Wiegart,, ${ }^{b, *}$ Jun Wang, \\ and Alan C. West ${ }^{\mathrm{a}, * *}$
}

${ }^{a}$ Department of Chemical Engineering, Columbia University, New York, New York 10027, USA

${ }^{b}$ Photon Sciences Directorate, Brookhaven National Laboratory, Upton, New York 11973, USA

\begin{abstract}
Transmission X-ray microscopy is utilized to monitor, in real time, the behavior of the $\mathrm{PbSO}_{4}$ film that is formed on $\mathrm{Pb}_{\text {in }} \mathrm{H}_{2} \mathrm{SO}_{4}$. Images collected from the synchrotron x-rays are coupled with voltammetric data to study the initial formation, the resulting passivation, and the subsequent reduction of the film. It is concluded with support from quartz-crystal-microbalance experiments that the initial formation of $\mathrm{PbSO}_{4}$ crystals occurs as a result of acidic corrosion. In addition, the film is shown to coalesce during the early stages of galvanostatic oxidation and to passivate as a result of morphological changes in the existing film. Finally, it is observed that the passivation process results in the formation of large $\mathrm{PbSO}_{4}$ crystals with low area-to-volume ratios, which are difficult to reduce under both galvanostatic and potentiostatic conditions.

(C) The Author(s) 2014. Published by ECS. This is an open access article distributed under the terms of the Creative Commons Attribution 4.0 License (CC BY, http://creativecommons.org/licenses/by/4.0/), which permits unrestricted reuse of the work in any medium, provided the original work is properly cited. [DOI: 10.1149/2.0141503jes] All rights reserved.
\end{abstract}

Manuscript submitted September 23, 2014; revised manuscript received November 10, 2014. Published December 9, 2014.

Lead-acid batteries have been a major part of the economy for over 100 years. ${ }^{1}$ Recently, they have seen significant use in next-generation energy storage applications (e.g., renewable energy storage, smartgrid buffering, and transportation) due to their high energy efficiency (up to $80 \%$ ), low capital cost, and the existence of a strong manufacturing, distribution, and recycling infrastructure. ${ }^{2}$ During discharge of a lead-acid battery, $\mathrm{Pb}$ is transformed into $\mathrm{PbSO}_{4}$ at the surface of the negative electrode through the following reaction with $\mathrm{H}_{2} \mathrm{SO}_{4}$ :

$$
\mathrm{Pb}+\mathrm{HSO}_{4}^{-} \stackrel{\text { discharge }}{\longrightarrow} \mathrm{PbSO}_{4}+\mathrm{H}^{+}+2 \mathrm{e}^{-}
$$

As a result of the reaction, the $\mathrm{Pb}$ electrode is coated by a $\mathrm{PbSO}_{4}$ film, which is reduced during charge. The performance and life-time of lead-acid batteries is greatly affected by the formation, growth, and resulting morphology of the $\mathrm{PbSO}_{4}$ film. ${ }^{3}$ For instance, one of the major factors limiting the lifetime of lead-acid batteries in high-rate, partial state-of-charge applications (i.e., electric and hybrid-electric vehicles) is the progressive sulfation of the negative electrode, whereby the $\mathrm{PbSO}_{4}$ film becomes irreversible and cannot be fully converted back into $\mathrm{Pb}$ after a sufficient charge. ${ }^{4,5}$

In the past 40 years, there has been a considerable effort focused on the formation of the $\mathrm{PbSO}_{4}$ film; however, there is still no general consensus on the exact mechanisms of nucleation and growth. For instance, both the Lakeman and Harrison groups studied the mechanisms of $\mathrm{PbSO}_{4}$ formation and suggested a dissolution-precipitation mechanism at low overpotentials with solid-state nucleation-and-growth occurring at high overpotentials. ${ }^{6-11}$ Later work by Hall and Wright, which was further developed by Varela et al., suggested that both mechanisms (dissolution-precipitation and solid-state nucleation-andgrowth) occur simultaneously in a complex manner which results in a bi-layered salt film with different properties for each layer. They suggested that passivation resulted from large crystals forming on top of a porous film as a result of a dissolution-precipitation mechanism. ${ }^{12-14}$ More recently, Yamaguchi et al. have concluded that only a single layer of $\mathrm{PbSO}_{4}$ forms as a result of a dissolution-precipitation mechanism and that sulfation may result from the chemical re-crystallization of electrochemically formed $\mathrm{PbSO}_{4} .{ }^{15}$

Most of the early studies on $\mathrm{PbSO}_{4}$ formation relied on the interpretation of voltammetric data to indirectly understand the formation processes on $\mathrm{Pb}$. Potentiostatic pulses and voltammetric sweeps were applied to the electrode, while the resulting current responses were measured and analyzed. Later, attempts were made to provide visual evidence by combining the same voltammetric techniques with

\footnotetext{
*Electrochemical Society Student Member

**Electrochemical Society Active Member.

${ }^{\mathrm{z} E-m a i l: k w k 2111 @ \text { columbia.edu }}$
}

atomic force microscopy (AFM). The AFM studies were able to obtain valuable information on the effects of operating conditions (e.g., open circuit standing time and cyclic voltammetry sweep rate) and the impact of electrolyte additives on the size and growth rates of the $\mathrm{PbSO}_{4}$ crystals. ${ }^{15-20}$ Further advancement of this in situ work would require a new technique that overcomes the small viewing window ( 25 to $100 \mu \mathrm{m}^{2}$ ) and slow acquisition time (52 sec per image) associated with AFM. A larger viewing window and a faster acquisition rate would make it possible to capture inhomogeneities in crystal formation and to better quantify growth. In addition, these experiments could be further improved through the use of constant current (galvanostatic) operating conditions. Electrochemical testing of full scale battery systems is typically done using constant current cycling at variable C-rates. ${ }^{21-23}$ Therefore, a fundamental understanding of $\mathrm{PbSO}_{4}$ growth under these conditions could yield valuable information which can be directly related to lead-acid battery performance. In particular, this understanding could help to further identify methods for significantly reducing irreversible or hard sulfation.

This work seeks to elucidate the mechanisms of $\mathrm{PbSO}_{4}$ film formation on $\mathrm{Pb}$ in $\mathrm{H}_{2} \mathrm{SO}_{4}$ using in situ transmission X-ray microscopy (TXM). TXM is a newly developed imaging technique with a large field of view $\left(1600 \mu \mathrm{m}^{2}\right)$, which is capable of producing X-ray micrographs at fast acquisition rates (up to one second time intervals) and with sub-40 nm resolutions. The formation, growth, and reduction of $\mathrm{PbSO}_{4}$ on $\mathrm{Pb}$ in $\mathrm{H}_{2} \mathrm{SO}_{4}$ are monitored, in real time, under potentiostatic and galvanostatic operating conditions. In addition, quartz-crystalmicrobalance experiments are conducted to support the voltammetric and visual data collected from the TXM. In the following sections, the in situ set-up is presented along with an investigation of the initial growth, passivation, and reduction of the $\mathrm{PbSO}_{4}$ film.

\section{Experimental}

Cell design. - The visualization of the growth and reduction of $\mathrm{PbSO}_{4}$ on $\mathrm{Pb}$ with synchrotron $\mathrm{X}$-rays was made possible with the use of an in-house designed, in situ, micro-electrochemical cell. The design of the cell is shown in Figure 1. The $\mathrm{Pb}$ electrode was formed by sputter coating a 20-nm thick strip of $\mathrm{Au} / \mathrm{Pd}$ on top of a translucent PET film (Fig. 1, part $i v$ ). Next, a $0.5-\mu \mathrm{m}$ thick layer of $\mathrm{Pb}$ was electroplated on the Au/Pd strip using a Pb-plating bath continuously stirred at $200 \mathrm{rpm}$ and consisting of $375 \mathrm{~g} / \mathrm{L}$ lead fluoborate, $22.5 \mathrm{~g} / \mathrm{L}$ fluoboric acid, $30 \mathrm{~g} / \mathrm{L}$ boric acid, and $5.3 \mathrm{~g} / \mathrm{L}$ peptone. ${ }^{24}$ The plating was conducted at a constant current density of $-18 \mathrm{~mA} \mathrm{~cm}^{-2}$ in a two-electrode system. A solid $\mathrm{Pb}$ sheet with a surface area that is $10 \times$ greater than the cathode area served as the counter electrode. 


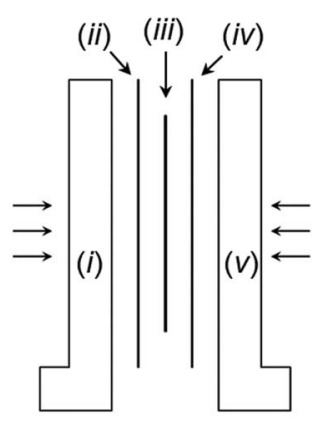

i) Polycarbonate brace w/
inlet/outlet holes

ii) PET (50 $\mu \mathrm{m}$ thick) $w /$ inlet/outlet holes

iii) Silicon gasket (127 $\mu \mathrm{m}$ thick)

iv) PET w/ strip of $0.5 \mu \mathrm{m}$ thick $\mathrm{Pb}$

v) Polycarbonate brace

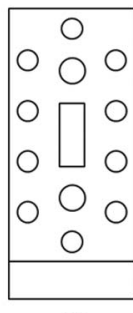

(i)

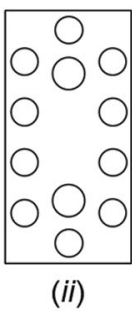

(ii)

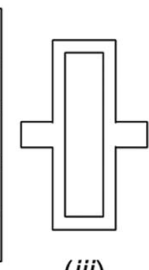

(iii)

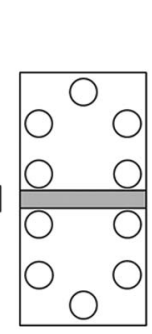

(iv)

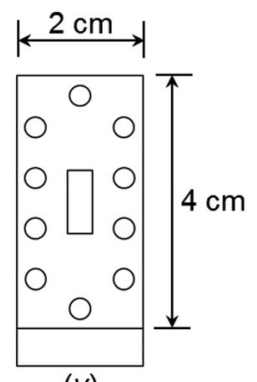

(v)
Figure 1. Design of in situ, micro-electrochemical cell used to monitor $\mathrm{PbSO}_{4}$ growth on $\mathrm{Pb}$ using synchrotron $\mathrm{x}$-rays.

After plating, the PET film was rinsed with de-ionized water, dried with compressed air, and immediately assembled into the in situ cell.

In the cell, the electrochemically active area $\left(0.18 \mathrm{~cm}^{2}\right)$ was defined using a silicon gasket (Fig. 1, part iii), which was sandwiched between two PET films (Fig. 1, parts $i i$ and $i v$ ). The gasket was $127 \mu \mathrm{m}$ thick (before compression) and, along with defining the active area, also provided a channel for the $\mathrm{H}_{2} \mathrm{SO}_{4}$. The electrical connection was made to the $\mathrm{Pb}$ electrode by a $38-\mu \mathrm{m}$ thick copper strip that was placed in between the gasket and the $\mathrm{Pb}$ (Fig. 2c). The whole cell was held in place by two polycarbonate braces, which were bolted together. Each brace contained a hollow window to provide a path for the synchrotron X-rays, which were only transmitted through the PET films, $\mathrm{H}_{2} \mathrm{SO}_{4}$, and $\mathrm{Pb}$. One of the braces and the PET film without a)

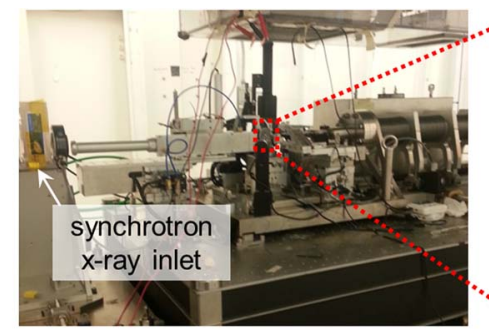

b)

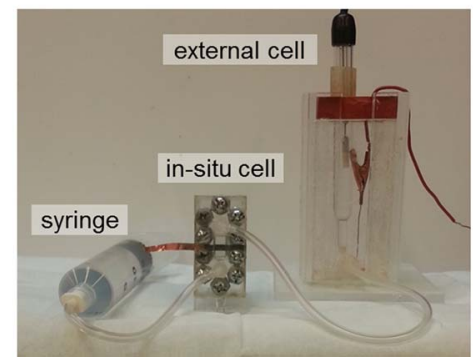

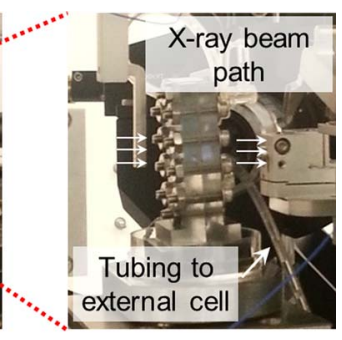

c)

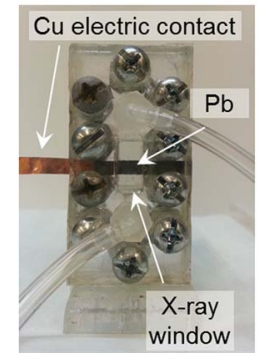

Figure 2. Experimental set-up for the in situ, electrochemical experiments. a) Placement of the in situ, micro-electrochemical cell in the TXM at Brookhaven National Laboratory. b) Image of the experimental system (i.e., syringe, in situ cell, and external cell) outside of the TXM. c) Close-up image of the in situ cell. the $\mathrm{Pb}$ also contained inlet/outlet holes for the electrolyte (Fig. 1, parts $i$ and $i$ ). The polycarbonate brace (Fig. 1, part $i$ ) was fitted with landings for connection to tubing.

TXM set-up and procedure.- During the experiment, the in situ cell was positioned in the transmission $\mathrm{X}$-ray microscope with the $\mathrm{X}$-ray beam penetrating through the $\mathrm{Pb}$ in a direction normal to the surface (Fig. 2a). Using flow tubes, the top of the in situ cell was connected to an external cell, which was placed outside of the beam flight-path. A $\mathrm{Hg} \mid \mathrm{Hg}_{2} \mathrm{SO}_{4}$ reference electrode in $4.6 \mathrm{M} \mathrm{H}_{2} \mathrm{SO}_{4}$ and a platinum counter electrode were placed inside the external cell (Fig. 2b). A syringe was connected to the bottom of the in situ cell and used to fill the entire system with $\mathrm{H}_{2} \mathrm{SO}_{4}$. The experiment was conducted with $4.6 \mathrm{M} \mathrm{H}_{2} \mathrm{SO}_{4}$, which was deaerated for 3 hours with argon gas.

The electrochemical growth and reduction of the film was controlled using a BioLogic VMP3 potentiostat, which was connected to all three electrodes - the lead electrode in the in situ cell and the reference and counter electrodes in the external cell. Prior to the experiment, galvanostatic electrochemical impedance spectroscopy (EIS) was conducted with a bias current equal to $0 \mu \mathrm{A}$, a frequency range from $10 \mathrm{kHz}$ to $100 \mathrm{mHz}$, and an amplitude of $\pm 10 \mu \mathrm{A} \mathrm{cm} \mathrm{cm}^{-2}$. The inherent ohmic resistance of the setup $(3466 \Omega)$ was determined from the high frequency intercept on the real axis of the Nyquist plot. ${ }^{25}$ This value was used to correct for ohmic drop between the reference and $\mathrm{Pb}$ electrodes (i.e., iR compensation) during the galvanostatic experiments. The full experimental procedure (without the EIS) is described in Figure 3, which includes the current and voltage of the system. All times in the remaining figures throughout the paper are reported in reference to Figure 3. To start the experiment, the $\mathrm{Pb}$ was first held at constant voltages of $-1.1 \mathrm{~V}$ and $-1.2 \mathrm{~V}$ for 30 minutes (regions ' $\mathrm{a}$ ' and ' $\mathrm{b}$ ') in order to reduce any $\mathrm{PbSO}_{4}$ that formed on the $\mathrm{Pb}$ while sitting in $\mathrm{H}_{2} \mathrm{SO}_{4}$. Next, the working electrode was held at the open-circuit voltage (OCV) for 2 minutes (region ' $c$ '), followed by a galvanostatic oxidation (region 'd') at $50 \mu \mathrm{A} \mathrm{cm} \mathrm{cm}^{-2}$ with a cutoff voltage of $-0.87 \mathrm{~V}(-0.84 \mathrm{~V}$ before correcting for ohmic drop). During the oxidation, $\mathrm{PbSO}_{4}$ was formed on $\mathrm{Pb}$. After reaching the cutoff voltage, the $\mathrm{Pb}$ was held at $\mathrm{OCV}$ for 2 minutes (region 'e') and then galvanostatically reduced (region ' $\mathrm{f}$ ') at $-50 \mu \mathrm{A} \mathrm{cm}{ }^{-2}$ with a cutoff voltage of $-1.17 \mathrm{~V}(-1.2 \mathrm{~V}$ before correcting for ohmic drop). Finally, a potentiostatic reduction was performed for 30 minutes at $-1.1 \mathrm{~V}$ (region ' $\mathrm{g}$ ') in an attempt to reduce all the remaining $\mathrm{PbSO}_{4}$ back to $\mathrm{Pb}$.

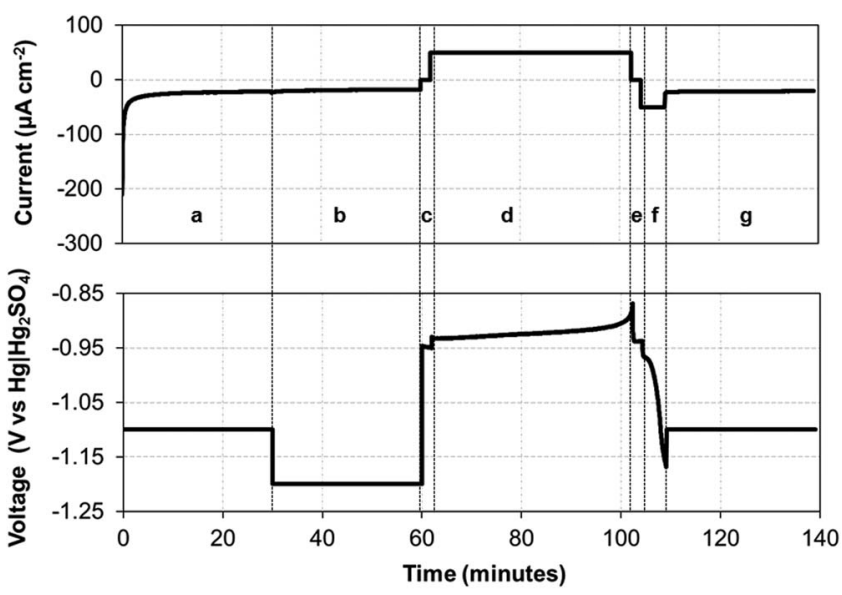

Figure 3. Voltage and current data during in situ experiment. Description of regions: (a) $-1.1 \mathrm{~V}$ for $30 \mathrm{~min}$; (b) $-1.2 \mathrm{~V}$ for $30 \mathrm{~min}$; (c) OCV for $2 \mathrm{~min}$; (d) oxidation at $50 \mu \mathrm{A} \mathrm{cm}^{-2}$ with a cut off voltage of $-0.87 \mathrm{~V}$; (e) OCV for $2 \mathrm{~min}$; (f) reduction at $-50 \mu \mathrm{A} \mathrm{cm} \mathrm{cm}^{-2}$ with a cut off voltage of $-1.17 \mathrm{~V}$; (g) $-1.1 \mathrm{~V}$ for $30 \mathrm{~min}$. 

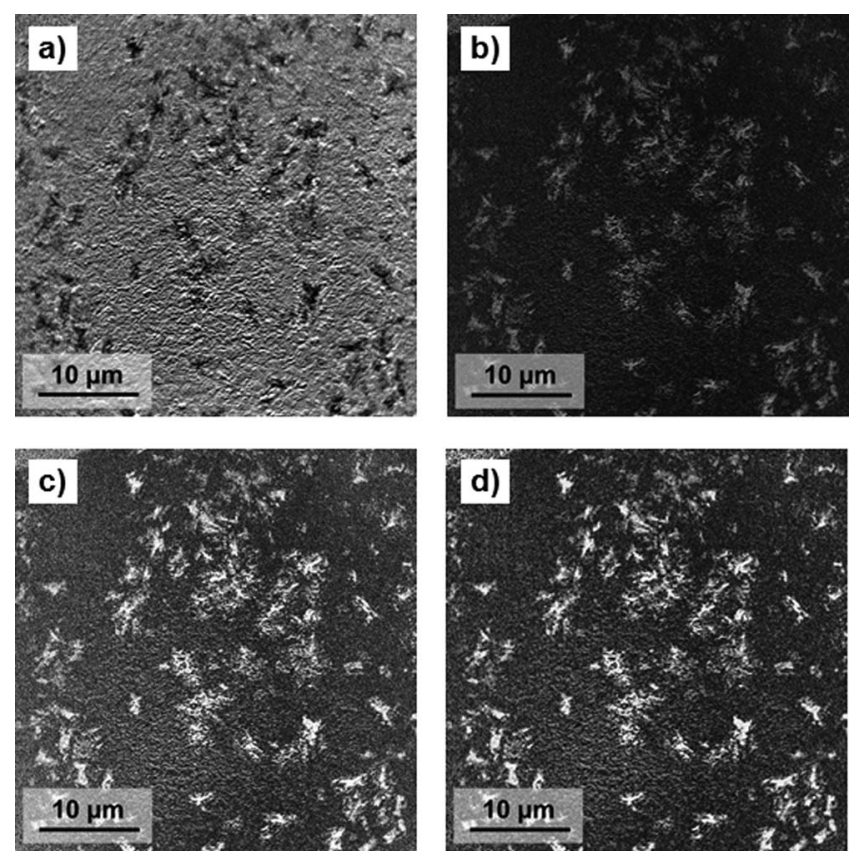

Figure 4. Processing of image taken at $t=62$ min: (a) original image, (b) difference with $\mathrm{Pb}$ background (i.e., image taken at $t=60 \mathrm{~min}$ ), (c) contrast correction, (d) pixel outlier removal.

Transmission X-ray microscopy. - The in situ transmission X-ray microscopy (TXM) was done at the X8C beamline of the National Synchrotron Light Source at Brookhaven National Laboratory. TXM is a non-destructive, nanoscale resolution, highly penetrative hard $\mathrm{X}$-ray imaging technique in which the sample environment can be easily controlled via the development and implementation of in situ environmental apparatuses. ${ }^{26}$ In situ imaging was done at an X-ray energy of $8 \mathrm{keV}$ with a large $40 \times 40 \mu \mathrm{m}\left(1600 \mu \mathrm{m}^{2}\right)$ field of view and an exposure time of 20 seconds for each image. The moderate exposure time made it possible to generate a clear image by binning a $2 \times 2$ pixel region using the $2 \mathrm{k} \times 2 \mathrm{k} C \mathrm{CD}$ camera, resulting in a pixel size of $39 \mathrm{~nm}$. At the start of the in situ experiment, five background images were collected of the lead sample and used for pixel-by-pixel normalization. Figure 4a shows an example of a TXM image after normalization. The image was taken during the galvanostatic oxidation at $t=62$ minutes.

Additional refinement of the in situ images was done using ImageJ software in order to better visualize the nucleation and growth processes of the $\mathrm{PbSO}_{4}$ film. ${ }^{27}$ In light of this additional processing, TXM images which were only altered through normalization with the $\mathrm{Pb}$ background are considered un-processed. Figure 4 shows the three-step refinement process for a single TXM image. In the first step, an image calculator is used to take the pixel-by-pixel difference of the 8-bit grayscale values of two images: the image in question (Fig. 4a) and an un-processed image of pure $\mathrm{Pb}$ taken during OCV at $t=60$ minutes into the experiment. The difference operator removes background features and enhances the $\mathrm{PbSO}_{4}$ crystals, as shown in Figure $4 \mathrm{~b}$. For the next step, a contrast adjustment is performed on the image by setting the maximum 8-bit gray scale value to 100 and adjusting the respective pixel lookup tables (Fig. 4c). Finally, a pixel outlier removal operation is performed for both dark and bright outliers, which uses a pixel radius of two and an 8-bit grayscale threshold of $50 .^{28}$ The final, processed image after all three steps is shown in Figure 4d.

Quartz crystal microbalance.- The quartz-crystal-microbalance (QCM) experiment was conducted using a PLO-10i phase lock oscillator (Maxtex, Inc.) equipped with a Teflon crystal holder (model no. CHC-100). The experiment employed a $5 \mathrm{MHz}$ AT-cut, polished quartz crystal, and the resonance frequency from the crystal was monitored using a Hewlet-Packard 53131 A frequency counter. ${ }^{29}$ The initial electrode was comprised of a platinum coating on top of a titanium seed layer. In order to obtain a Pb electrode, a $10-\mu \mathrm{m}$ thick layer of $\mathrm{Pb}$ was electrodeposited on top of the platinum electrode using the plating procedure previously described herein. The constant current plating was controlled using a $\mu$ AutolabIII potentiostat (Metrohm USA, Inc.), and the electrode was contained in the Teflon holder. After plating, the quartz crystal was removed from the Teflon holder, rinsed with deionized water, and dried with nitrogen gas. The quartz crystal was then placed back in the holder and submersed in $100 \mathrm{~mL}$ of $4.6 \mathrm{M} \mathrm{H}_{2} \mathrm{SO}_{4}$ for the QCM experiment. The $\mathrm{H}_{2} \mathrm{SO}_{4}$ was purged with argon gas for 3 hours prior to the experiment. Along with the $\mathrm{Pb}$ coated quartz crystal, the QCM set-up included a $\mathrm{Hg} \mid \mathrm{Hg}_{2} \mathrm{SO}_{4}$ reference electrode in $4.6 \mathrm{M}$ sulfuric acid to monitor the voltage and a platinum counter electrode.

\section{Results and Discussion}

TXM results. - potentiostatic reductions. - Figure 5 shows the results of the potentiostatic reductions at $-1.1 \mathrm{~V}$ and $-1.2 \mathrm{~V}$, which were performed at the beginning of the TXM experiment (Fig. 3, regions ' $a$ ' and ' $b$ '). Each numbered point on the voltage curve corresponds to the time the respective image was taken. The objective of these procedures was to remove any $\mathrm{PbSO}_{4}$ film that had grown on the $\mathrm{Pb}$ surface during the five-minute period between filling the in situ, micro-electrochemical cell with $\mathrm{H}_{2} \mathrm{SO}_{4}$ and the start of the experiment. Image 1, in Figure 5, shows the presence of a surface film at the start of the experiment. A similar film was observed by Yamaguchi et al. for a $\mathrm{Pb}$ electrode immersed in $0.05 \mathrm{M} \mathrm{H}_{2} \mathrm{SO}_{4}$ for 20 minutes using AFM. ${ }^{20}$ There are two possible mechanisms for the formation of the initial $\mathrm{PbSO}_{4}$ film. First, dissolved oxygen present in the electrolyte could form $\mathrm{PbSO}_{4}$ through the following reaction: ${ }^{3,30}$

$$
\mathrm{Pb}+\frac{1}{2} \mathrm{O}_{2}+\mathrm{H}_{2} \mathrm{SO}_{4} \rightarrow \mathrm{PbSO}_{4}+\mathrm{H}_{2} \mathrm{O}, \quad \Delta \mathrm{G}^{0}=-306.5 \mathrm{~kJ} \mathrm{~mol}^{-1}
$$

Due to the fast kinetics of the electrochemical reduction of oxygen on the $\mathrm{Pb}$ electrode, the reaction in Eq. 2 is diffusion-limited, i.e. the reaction rate is controlled by the mass transfer of oxygen to the $\mathrm{Pb}$ surface. ${ }^{31}$ Therefore, any oxygen present near the electrode will readily cause the formation of $\mathrm{PbSO}_{4}$. Despite the fast kinetics of the oxygen reaction, this mechanism is unlikely since the electrolyte in the current study was deaerated with argon before the experiment. Therefore, the film was most likely formed as a result of acid corrosion via the following reaction: $: 30$

$$
\mathrm{Pb}+\mathrm{H}_{2} \mathrm{SO}_{4} \rightarrow \mathrm{PbSO}_{4}+\mathrm{H}_{2} \quad \Delta \mathrm{G}^{0}=-69.3 \mathrm{~kJ} \mathrm{~mol}^{-1}
$$

According to the potential vs. $\mathrm{pH}$ (Pourbaix) diagram for the $\mathrm{Pb} / \mathrm{H}_{2} \mathrm{SO}_{4}$ system, the corrosion reaction in Eq. 3 is thermodynamically unavoidable at the low $\mathrm{pH}$ of the $4.6 \mathrm{M} \mathrm{H}_{2} \mathrm{SO}_{4} .{ }^{1}$

Despite the initial presence of the film, images 2-5 in Figure 5 clearly depict that the constant potential procedures succeed in reducing the film to bare $\mathrm{Pb}$. The majority of the surface film is reduced during the first 12 minutes at $-1.1 \mathrm{~V}$ (Fig. 5, image 3), and all but a few crystals remain after 30 minutes (Fig. 5, image 4). Although most of the $\mathrm{PbSO}_{4}$ is consumed within 30 minutes, there is still a constant cathodic current, which can be attributed to hydrogen evolution on the surface of the $\mathrm{Pb}$. At $t=60$ minutes into the experiment (Fig. 5, image 5), no surface film is present, providing a clean $\mathrm{Pb}$ sample as a starting point for the remainder of the TXM experiment. $O C V$ and galvanostatic oxidation.-In order to investigate the nucleation and growth of the $\mathrm{PbSO}_{4}$ film, after the potentiostatic reduction step, the $\mathrm{Pb}$ electrode was held at OCV for two minutes and then oxidized at a constant current density of $50 \mu \mathrm{A} \mathrm{cm}{ }^{-2}$. The voltage response and resulting TXM images of the OCV and initial oxidation can be found in Figure 6. The numbered regions on the voltage vs. time graph indicate the exposure time for each image. From image 2 of the figure, it appears that the nucleation of $\mathrm{PbSO}_{4}$ crystals starts before the oxidation current is applied, indicating that the initial 

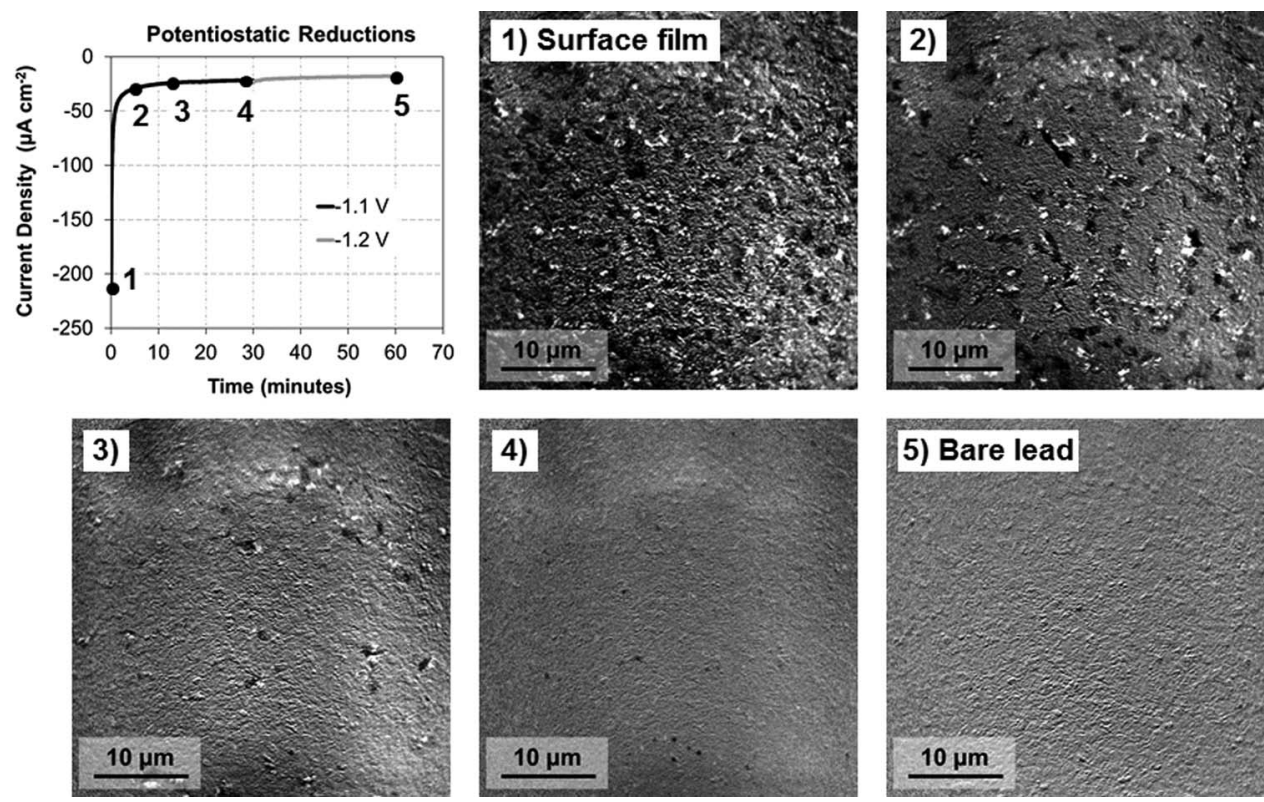

Figure 5. Current response of potentiostatic reductions (regions ' $a$ ' and 'b' in Fig. 3) and corresponding, un-processed TXM images.

formation of $\mathrm{PbSO}_{4}$ is due to an electrochemical corrosion reaction. The previously described acidic corrosion of $\mathrm{Pb}$ (Eq. 3) is most likely responsible for the initial nucleation. Image 2 also indicates that the onset of the corrosion reaction is rapid, with crystals up to $1 \mu \mathrm{m}$ in diameter visible 1.5 minutes into the open-circuit voltage measurement. For a lead-acid battery at OCV, this rapid corrosion will occur on the negative electrode and has been shown to decrease the capacity of the electrode at rates of up to $0.5 \%$ per day. ${ }^{32}$

Figure 6 also makes it possible to monitor the growth of the film. After the nucleation process, the film continues to grow, coating the $\mathrm{Pb}$ surface as it spreads out from the initial nucleation sites. In addition to the spreading of the film, a comparison of images 2 and 3 indicates an increase in the total number of $\mathrm{PbSO}_{4}$ crystals during growth. This suggests that $\mathrm{PbSO}_{4}$ crystals are constantly formed during the growth process, which would correspond to progressive nucleation. It is important to note that an increase in total crystals was observed for all images between $t=61.5$ to 63 minutes. Therefore, the increase in crystals between images 2 and 3 was not a result of the application of an oxidation current, but a demonstration of the consistent formation of nuclei. This fact is clearly shown in Figure 7, where the crystal densities from several TXM images are plotted as a function of time. These observations of a progressive nucleation are in contradiction with the findings of several authors who have interpreted chronoamperometry and concluded that the film forms as a result of an instantaneous nucleation process. ${ }^{11-13}$ This discrepancy may be due to the fact that the previous nucleation and growth studies are typically reported for high anodic overpotentials $(>50 \mathrm{mV})$ where solid-state reactions are assumed to dominate. The present oxidation occurs at low anodic overpotentials $(<20 \mathrm{mV})$ where a dissolution-precipitation mechanism is thought to occur. ${ }^{7}$
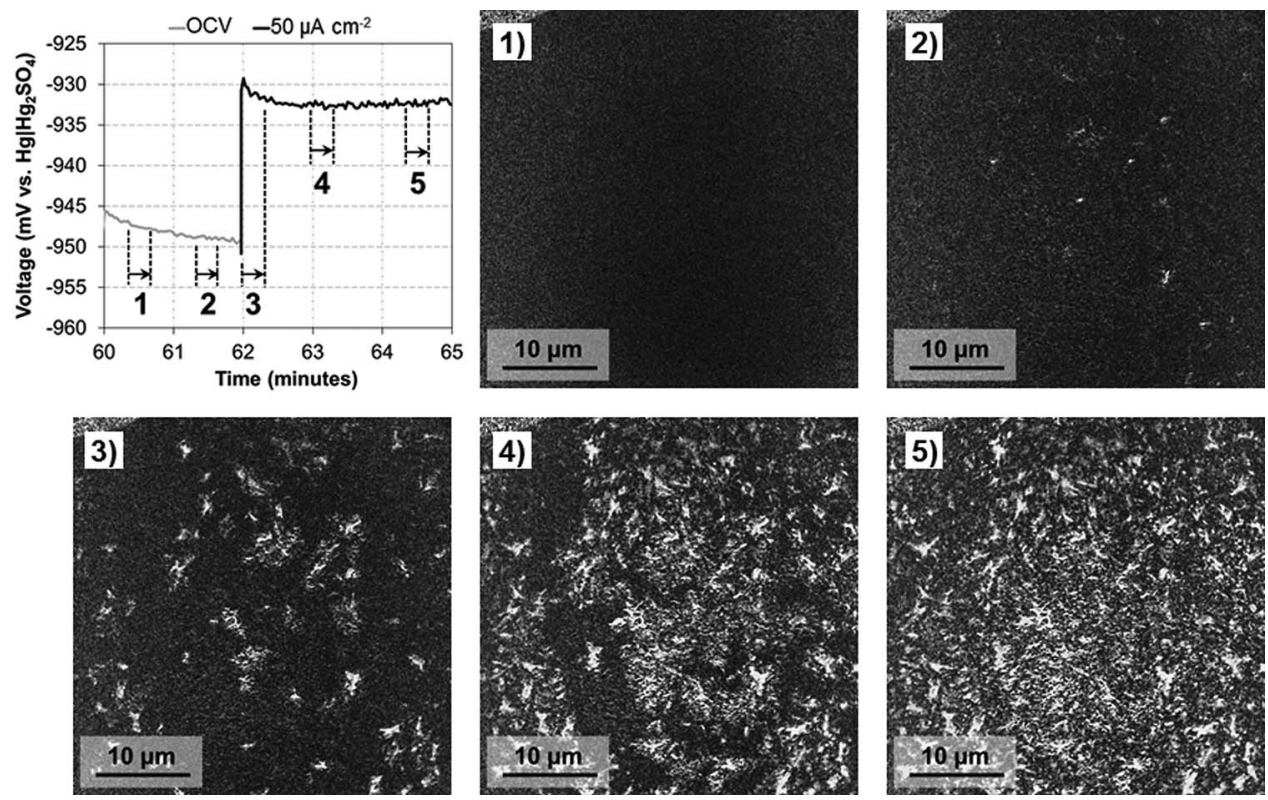

Figure 6. Voltage response of open-circuit voltage and initial stage of galvanostatic oxidation (regions 'c' and 'd' in Fig. 3, respectively) and corresponding TXM images. 


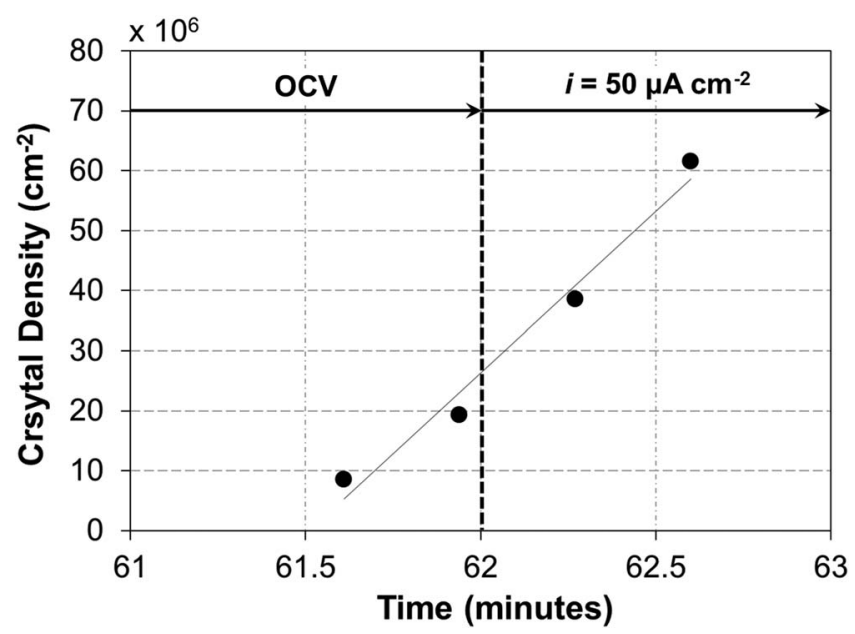

Figure 7. Lead sulfate crystal density at end of OCV and start of galvanostatic oxidation (regions ' $c$ ' and 'd' in Fig. 3, respectively). $\mathrm{R}^{2}=0.98$.

These conclusions suggest that the progressive nucleation of $\mathrm{PbSO}_{4}$ observed in Figs. 6 and 7 results from a dissolution-precipitation mechanism.

At $t=64.5$ minutes (Fig. 6, image 5), the film is fully coalesced, and the $\mathrm{Pb}$ electrode is completely covered by $\mathrm{PbSO}_{4}$. This occurs three minutes after the first $\mathrm{PbSO}_{4}$ crystal is observed (Fig. 6, image 2), and indicates that the $\mathrm{Pb}$ electrode is fully covered during the early stages of the oxidation experiment. Figure 8 shows the voltage response of the complete oxidation and the resulting TXM images. As a point of reference, image 1 in Figure 8 and image 3 in Figure 6 are the same image. In this experiment, the passivation of the electrode, as indicated by the rapid increase in anodic voltage, occurs at $t=102$ minutes. A cutoff voltage of $-0.87 \mathrm{~V}$ was used to indicate the end of $\mathrm{PbSO}_{4}$ oxidation and to prevent the formation of $\mathrm{PbO}$ compounds at higher anodic potentials. ${ }^{33}$ Since the $\mathrm{PbSO}_{4}$ film fully covers the $\mathrm{Pb}$ electrode several minutes into the process, the majority of the galvanostatic oxidation ( $97.5 \%$ of the total time) corresponds to the growth of a pre-existing, fully coalesced film (Fig. 8, images 2 to 5). The passivation (image 5) can, therefore, be attributed to mor- phological changes in the $\mathrm{PbSO}_{4}$ film which impede the oxidation process. Earlier authors have suggested that passivation is caused by a thickening or reduction in porosity of the film, which restricts the mass transport of ions $\left(\mathrm{Pb}^{2+}\right.$ or $\left.\mathrm{SO}_{4}{ }^{2-}\right)$ to the reaction sites at or near the $\mathrm{Pb}$ surface. ${ }^{34,35}$ The TXM images in the present study support this conclusion.

Reduction of the $\mathrm{PbSO}_{4}$ film.-After the completion of the galvanostatic oxidation, a galvanostatic reduction (Fig. 3, region ' $f$ ') was conducted at $-50 \mu \mathrm{A} \mathrm{cm} \mathrm{cm}^{-2}$ in an attempt to reduce the passivating $\mathrm{PbSO}_{4}$ film back to $\mathrm{Pb}$. A cutoff voltage of $-1.17 \mathrm{~V}$ was used to indicate the end of $\mathrm{PbSO}_{4}$ reduction and to prevent excess gassing of hydrogen at the electrode. The voltage curve in Fig. 3 shows that the reduction of $\mathrm{PbSO}_{4}$ back to $\mathrm{Pb}$ is a rather inefficient reaction, with the reduction reaching the cutoff voltage in less than five minutes. The low efficiency can be attributed to the high applied current density, which caused the cutoff voltage to be reached before all the $\mathrm{PbSO}_{4}$ was reduced. Ekdunge et al. have shown that the diffusion and/or dissolution of $\mathrm{Pb}^{2+}$ ions are the rate-determining steps during the reduction of the $\mathrm{PbSO}_{4}$ electrode. ${ }^{36}$ It is possible that the applied current quickly exceeded the rates of these processes, causing a rapid increase in the overpotential in order to generate current via hydrogen evolution. A more complete reduction would be expected at lower current densities. By comparing the times of the galvanostatic reduction and oxidation procedures, it is reasonable to assume that up to $88 \%$ of the $\mathrm{PbSO}_{4}$ formed on the electrode surface during the galvanostatic oxidation remains at the end of the galvanostatic reduction. In an attempt to further reduce this excess film, a potentiostatic reduction of $-1.1 \mathrm{~V}$ was applied to the $\mathrm{Pb}$ electrode immediately after the galvanostatic reduction (Fig. 3, region ' $\mathrm{g}$ ').

Figure 9 shows the current response of the $-1.1 \mathrm{~V}$ potentiostatic reduction and the subsequent TXM images taken at the beginning and end of the technique. These images were only altered through normalization with the $\mathrm{Pb}$ background and were not processed with the ImageJ software. Image 1 shows the existence of well-defined $\mathrm{PbSO}_{4}$ crystals up to $4 \mu \mathrm{m}$ in diameter, which remained on the $\mathrm{Pb}$ surface at the end of the galvanostatic experiments. At the end of the potentiostatic reduction, these crystals appear to have shrunken in size but still remain on the surface (image 2). These images can be compared to those obtained during the potentiostatic reductions at the beginning of the experiment (Fig. 5). The $\mathrm{PbSO}_{4}$ crystals formed during the TXM experiment persist longer than those formed at open-circuit voltage. This is most likely due to the fact that the $\mathrm{PbSO}_{4}$ crystals in Fig. 9
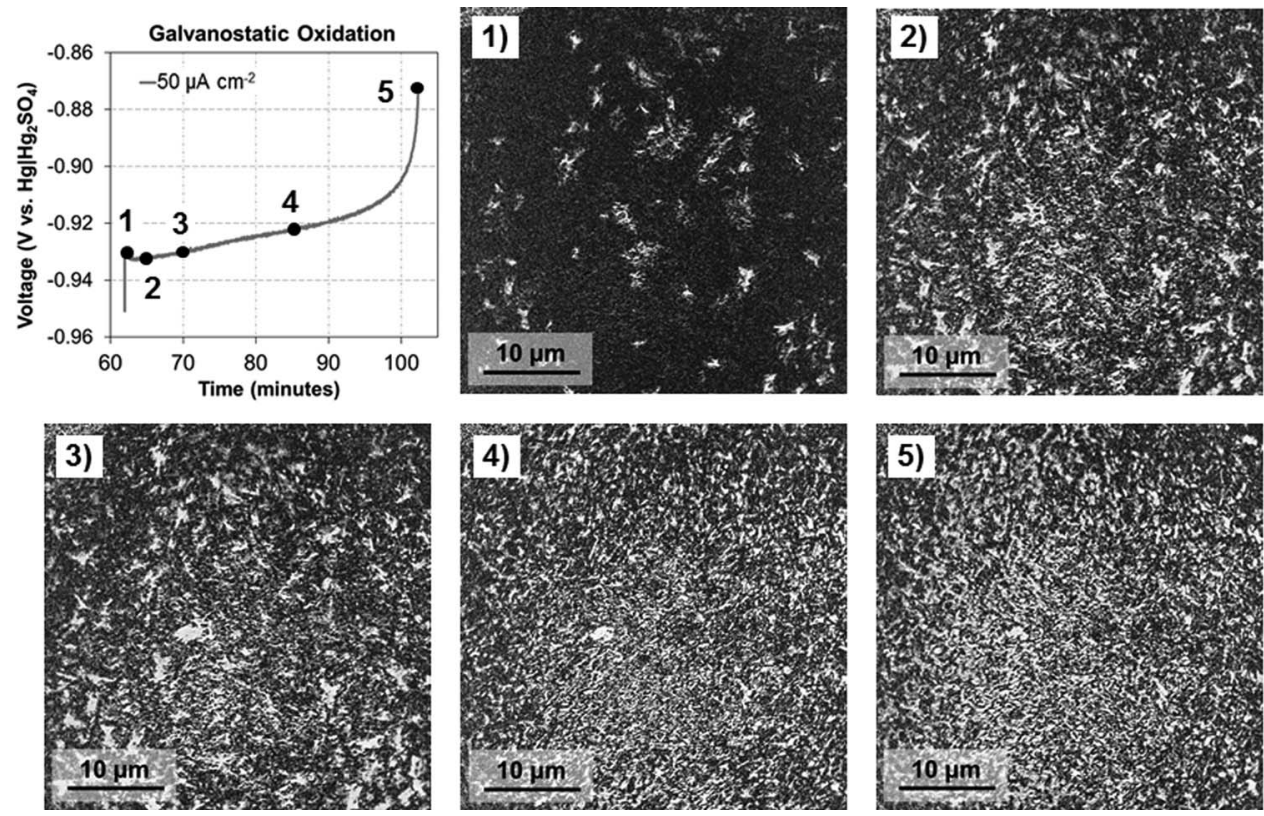

Figure 8. Voltage response of galvanostatic oxidation (region 'd' in Fig. 3) and corresponding TXM images. 

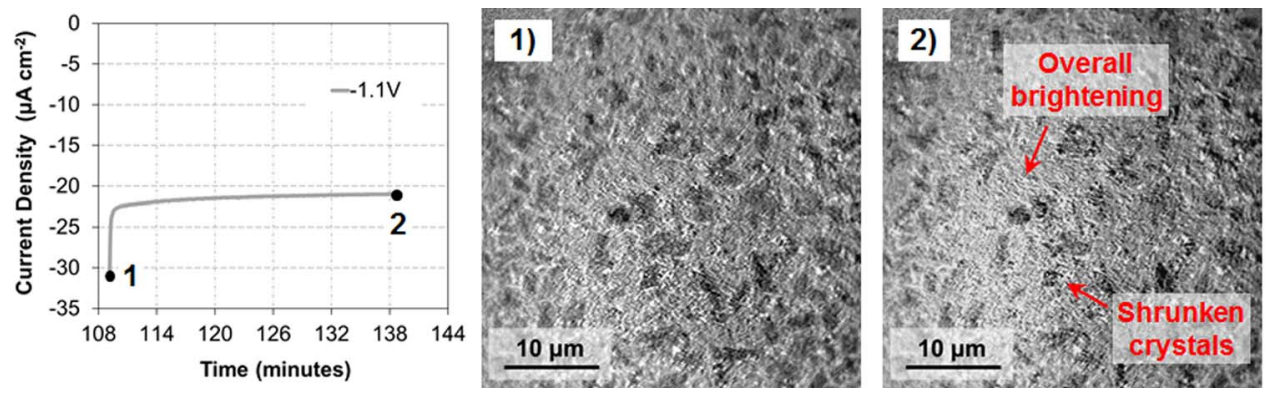

Figure 9. Current response of potentiostatic reduction performed after galvanostatic experiments (region 'g' in Fig. 3) and un-processed, TXM images before and after technique.

are much larger than those in Fig. 5, and therefore, they have a lower area-to-volume ratio. The lower surface area impedes the dissolution of the $\mathrm{PbSO}_{4}$, which is the first step in the reduction of the film. ${ }^{36}$ Although the same potential of $-1.1 \mathrm{~V}$ is applied to the electrode at the start (Fig. 3, region 'a') and end of the experiment (Fig. 3, region ' $g$ '), the current obtained from the electrode differs due to changes in $\mathrm{PbSO}_{4}$ crystal morphology. Similar results have been observed by Kanamura and Takehara, who were able to model the effects of crystal size on the reduction current obtained from cyclic voltammograms. ${ }^{37}$

In addition, image 2(Fig. 9) shows that the spaces between the large crystals appear to have brightened during the potentiostatic reduction, which corresponds to an increase in X-ray transmission through the sample. The increase in transmission can be attributed to the reduction of the $\mathrm{PbSO}_{4}$ film. The brightened area in image 2 is most likely the bare, $\mathrm{Pb}$ electrode which is exposed as a result of the $\mathrm{PbSO}_{4}$ reduction. Because no distinct crystals are observed in this region in image 1, the film between the large crystals most likely consists of smaller crystals whose morphology is indistinguishable using the TXM. This suggests that, while it was difficult for the large crystals to reduce, smaller $\mathrm{PbSO}_{4}$ crystallites were reduced. ${ }^{5,38}$ The existence of large and small crystals can be associated with the progressive nucleation of $\mathrm{PbSO}_{4}$ observed in Figures 6 and 7. The constant formation of new nuclei results in crystals of different sizes. An easily reduced $\mathrm{PbSO}_{4}$ film would be preferred in order to maximize the efficiency and to maintain the capacity of a lead-acid battery.

Quartz crystal microbalance.- In order to support the claims made herein of a high acidic corrosion rate for $\mathrm{Pb}$ in $\mathrm{H}_{2} \mathrm{SO}_{4}$, quartz crystal microbalance (QCM) experiments were performed. A QCM is able to detect small changes in mass on top of a quartz crystal by measuring the associated change in resonant frequency of the crystal. Sauerbrey was the first to recognize that the change in frequency of a quartz crystal can be directly related to the added mass through the following equation: ${ }^{39}$

$$
\Delta f=-C_{f} \times \Delta m
$$

where $\Delta f$ is the change in frequency, $\Delta m$ is the change in mass per unit area, and $C_{f}$ is a sensitivity factor, which is a fundamental property of the quartz crystal. It is defined as follows:

$$
C_{f}=\frac{\alpha 2 f_{0}^{2}}{\sqrt{\rho_{q} \mu_{q}}}
$$

where $f_{0}$ is the resonant frequency of the unloaded crystal, $\rho_{q}$ is the density of quartz, $\mu_{q}$ is the elastic shear modulus of quartz, and $\alpha$ is a dimensionless instrument constant. ${ }^{29}$ For the current set-up, $C_{f}=0.0566 \mathrm{~Hz} \mathrm{~cm}^{2} \mathrm{ng}^{-1}$.

In these experiments, a quartz crystal plated with a $10-\mu \mathrm{m}$ thick film of $\mathrm{Pb}$ was placed in $4.6 \mathrm{M} \mathrm{H}_{2} \mathrm{SO}_{4}$, and the change in mass per unit area was monitored over time. $\mathrm{A} \mathrm{Hg} \mid \mathrm{Hg}_{2} \mathrm{SO}_{4}$ reference electrode was used to monitor the open circuit voltage, and it was confirmed that the electrode was near the reversible $\mathrm{Pb} / \mathrm{PbSO}_{4}$ potential. Figure 10a shows the recorded mass change per unit area over a 30 minute period. Also included in the figure is the mass change per unit area detected by Taguchi et al. for a $\mathrm{Pb}$ electrode in $4.5 \mathrm{M} \mathrm{H}_{2} \mathrm{SO}_{4}$ using the same technique. ${ }^{40}$ Good agreement is observed between the two experiments. Both show a sharp initial rise in mass, which reaches a steady state $\sim 10$ minutes into the experiment. In order to compare the rate of corrosion with the oxidation rate used in the experiment, the mass change per unit area was converted into a corrosion current $\left(i_{\text {corr }}\right.$ $[=] \mu \mathrm{A} \mathrm{cm}^{-2}$ ). To accomplish this, the relative quantity of charge stored in the growing $\mathrm{PbSO}_{4}$ film was determined from the change in measured mass per unit area using the following equation:

$$
Q=\frac{n F \Delta m}{M W_{S O_{4}^{2-}}}
$$

where $F$ is Faraday's constant, $n$ is the number of $\mathrm{e}^{-}$passed per mole of $\mathrm{SO}_{4}{ }^{2-}$ reacting, $M W_{\mathrm{SO}_{4}^{2-}}$ is the molecular weight of $\mathrm{SO}_{4}{ }^{2-}$, and $Q$ has units of $\mathrm{C} \mathrm{cm}^{-2}$. This equation assumes that all the $\mathrm{PbSO}_{4}$ products remained on the surface, which is a reasonable assumption due to the low solubility of $\mathrm{PbSO}_{4}$ in $\mathrm{H}_{2} \mathrm{SO}_{4} \cdot{ }^{41}$

Once the change in the quantity of charge $(Q)$ was determined using Eq. 6, $i_{\text {corr }}$ was calculated from the first order derivative of the quantity of charge with respect to time:

$$
i_{\text {corr }}=\frac{d Q}{d t}
$$

a)

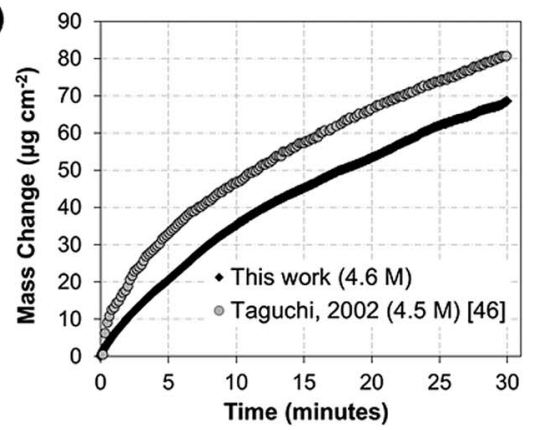

b)

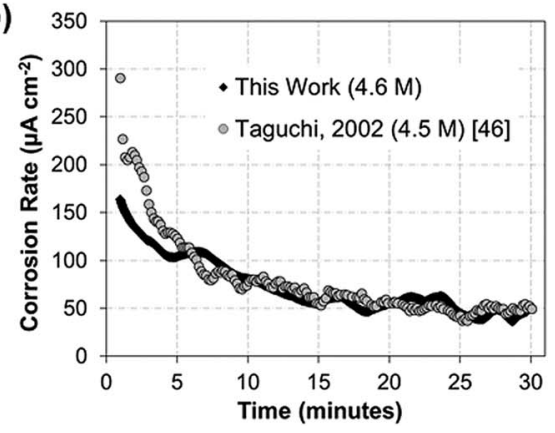

Figure 10. a) Mass change of $\mathrm{Pb}$ in $\mathrm{H}_{2} \mathrm{SO}_{4}$ determined using a quartz-crystal-microbalance. b) Corrosion rate calculated from slope of QCM results shown in (a). 
Figure $10 \mathrm{~b}$ depicts the change in $i_{\text {corr }}$ over the 30 minute experiment. After a high initial value, $i_{\text {corr }}$ appears to settle at a value equivalent to $50 \mu \mathrm{A} \mathrm{cm}^{-2}$. This is the same value used for the galvanostatic oxidation and reduction experiments performed in the TXM. It indicates that the acidic corrosion of $\mathrm{Pb}$ in $\mathrm{H}_{2} \mathrm{SO}_{4}$ is quite fast and is responsible for the nucleation of $\mathrm{PbSO}_{4}$ crystals observed during the open-circuit voltage measurements.

\section{Conclusions}

This work presents an investigation of the surface behavior of the $\mathrm{Pb} / \mathrm{PbSO}_{4}$ electrode in a lead-acid battery. In situ transmission X-ray microscopy was used to monitor, in real time, the formation, growth, and reduction of $\mathrm{PbSO}_{4}$ on $\mathrm{Pb}$ in $\mathrm{H}_{2} \mathrm{SO}_{4}$ under potentiostatic and galvanostatic operating conditions. The resulting TXM images were used to show that the initial nucleation of $\mathrm{PbSO}_{4}$ crystals occurred while the $\mathrm{Pb}$ electrode was held at an open-circuit voltage. Using a quartz-crystal microbalance, it was shown that this behavior could be attributed to the acidic corrosion of $\mathrm{Pb}$ in $\mathrm{H}_{2} \mathrm{SO}_{4}$.

During the early stages of film formation, TXM images depicted a progressive nucleation of $\mathrm{PbSO}_{4}$ crystals, which were concluded to form through a dissolution-precipitation mechanism. The data also showed that the $\mathrm{PbSO}_{4}$ film was fully coalesced across the surface of the $\mathrm{Pb}$ electrode during the early stages of the galvanostatic oxidation. Therefore, it was concluded that the passivation of the electrode was due to morphological changes in the existing $\mathrm{PbSO}_{4}$ film, which impeded the mass transport of reactants. In addition, the passivating film was shown to be stable and difficult to reduce. This behavior was attributed to the formation of a significant number of large crystals with low area-to-volume ratios, which hindered the dissolution of $\mathrm{PbSO}_{4}$.

\section{Acknowledgments}

K. W. K. greatly acknowledges the support of the National Science Foundation Graduate Research Fellowship under grant No. 1144155. Any opinions, findings, and conclusions or recommendations expressed in this material are those of the authors and do not necessarily reflect the views of the National Science Foundation.

This work was supported in part by the American Recovery and Reinvestment Act funding through Department of Energy, Office of Science, Office of Basic Energy Sciences. Use of the National Synchrotron Light Source, Brookhaven National Laboratory for this work was supported by the U.S. Department of Energy, Office of Science, Office of Basic Energy Sciences under Contract No. DEAC02-98CH10886.

\section{References}

1. P. Ruetschi, J. Power Sources, 2, 3 (1977).

2. K. Peters, in Valve-Regulated Lead-Acid Batteries, D. A. J. Rand, P. T. Moseley, J. Garche, and C. D. Parker, Editors, p. 135, Elsevier, The Netherlands (2004).

3. D. Pavlov, in Lead-Acid Batteries Science and Technology: A Handbook of Lead-Acid Battery Technology and Its Influence on the Product, p. 29, Elsevier Science Ltd., Amsterdam (2011).

4. P. Ruetschi, J. Power Sources, 127, 33 (2004).

5. D. U. Sauer, in Encyclopedia of Electrochemical Power Sources, J. Garche, Editor, p. 805, Elsevier, Amsterdam (2009).

6. G. Archdale and J. A. Harrison, J. Electroanal. Chem., 34, 21 (1972).

7. G. Archdale and J. A. Harrison, J. Electroanal. Chem., 39, 357 (1972).

8. A. N. Fleming and J. A. Harrison, Electrochim. Acta, 21, 905 (1976).

9. N. A. Hampson and J. B. Lakeman, Surf. Technol., 9, 97 (1979).

10. N. A. Hampson and J. B. Lakeman, J. Power Sources, 4, 21 (1979)

11. N. A. Hampson and J. B. Lakeman, J. Electroanal. Chem., 107, 177 (1980).

12. S. B. Hall and G. A. Wright, Corros. Sci., 31, 709 (1990).

13. F. E. Varela, M. E. Vela, J. R. Vilche, and A. J. Arvia, Electrochim. Acta, 38, 1513 (1993).

14. F. E. Varela, J. R. Vilche, and A. J. Arvia, Electrochim. Acta, 39, 401 (1994).

15. Y. Yamaguchi, M. Shiota, Y. Nakayama, N. Hirai, and S. Hara, J. Power Sources, 93 104 (2001).

16. I. Ban, Y. Yamaguchi, Y. Nakayama, N. Hirai, and S. Hara, J. Power Sources, 107, 167 (2002).

17. N. Hirai, S. Kubo, and K. Magara, J. Power Sources, 191, 97 (2009).

18. H. Vermesan, N. Hirai, M. Shiota, and T. Tanaka, J. Power Sources, 133, 52 (2004).

19. Y. Yamaguchi, M. Shiota, M. Hosokawa, Y. Nakayama, N. Hirai, and S. Hara, J. Power Sources, 102, 155 (2001).

20. Y. Yamaguchi, M. Shiota, Y. Nakayama, N. Hirai, and S. Hara, J. Power Sources, 85 , $22(2000)$.

21. B. O. Myrvold and D. Pavlov, J. Power Sources, 85, 92 (2000).

22. D. Pavlov, B. O. Myrvold, T. Rogachev, and M. Matrakova, J. Power Sources, 85, 79 (2000).

23. D. P. Boden, J. Arias, and F. A. Fleming, J. Power Sources, 95, 277 (2001).

24. S. Hirsch and C. Rosenstein, Met. Finish., 100(Supplement 1), 291 (2002).

25. J. R. Macdonald and W. B. Johnson, in Impedance Spectroscopy Theory, Experiment, and Applications, 2nd ed., E. Barsoukov and J. R. Macdonald, Editors, p. 1, WileyInterscience, Hoboken, N.J. (2005).

26. J. Wang, Y. C. K. Chen, Q. X. Yuan, A. Tkachuk, C. Erdonmez, B. Hornberger, and M. Feser, Appl. Phys. Lett., 100, 143107 (2012).

27. C. A. Schneider, W. S. Rasband, and K. W. Eliceiri, Nature Methods, 9, 671 (2012).

28. T. Ferreira and W. S. Rasband, ImageJ User Guide - IJ 1.46, imagej.nih.gov/ ij/docs/guide/ (2010-2012).

29. J. J. Kelly, K. M. A. Rahman, C. J. Durning, and A. C. West, J. Electrochem. Soc., 145, 492 (1998)

30. P. Ruetschi and R. T. Angstadt, J. Electrochem. Soc., 105, 555 (1958)

31. L. M. Baugh, K. L. Bladen, and F. L. Tye, J. Electroanal. Chem., 145, 355 (1983).

32. A. J. Salkind, A. G. Cannone, and F. A. Trumbure, in Handbook of Batteries, 3rd ed., D. Linden and T. B. Reddy, Editors, p. 23.1, McGraw-Hill, New York (2002).

33. D. Pavlov, Electrochim. Acta, 13, 2051 (1968).

34. P. Ruetschi and R. T. Angstadt, J. Electrochem. Soc., 111, 1323 (1964).

35. D. Pavlov and R. Popova, Electrochim. Acta, 15, 1483 (1970).

36. P. Ekdunge, K. V. Rybalka, and D. Simonsson, Electrochim. Acta, 32, 659 (1987)

37. K. Kanamura and Z. Takehara, J. Electrochem. Soc., 139, 345 (1992).

38. Y. L. Guo, M. D. Wu, and S. N. Hua, J. Power Sources, 64, 65 (1997)

39. G. Sauerbrey, Z. Phys., 155, 206 (1959).

40. M. Taguchi and H. Sugita, J. Power Sources, 109, 294 (2002).

41. D. N. Craig and G. W. Vinal, J. Res. Natl. Bur. Stand., 22, 55 (1939). 